Prepared for the U.S. Department of Energy

under Contract DE-AC05-76RL01830

\title{
CCSI Risk Estimation: An Application of Expert Elicitation
}

DW Engel

AC Dalton

October 2012

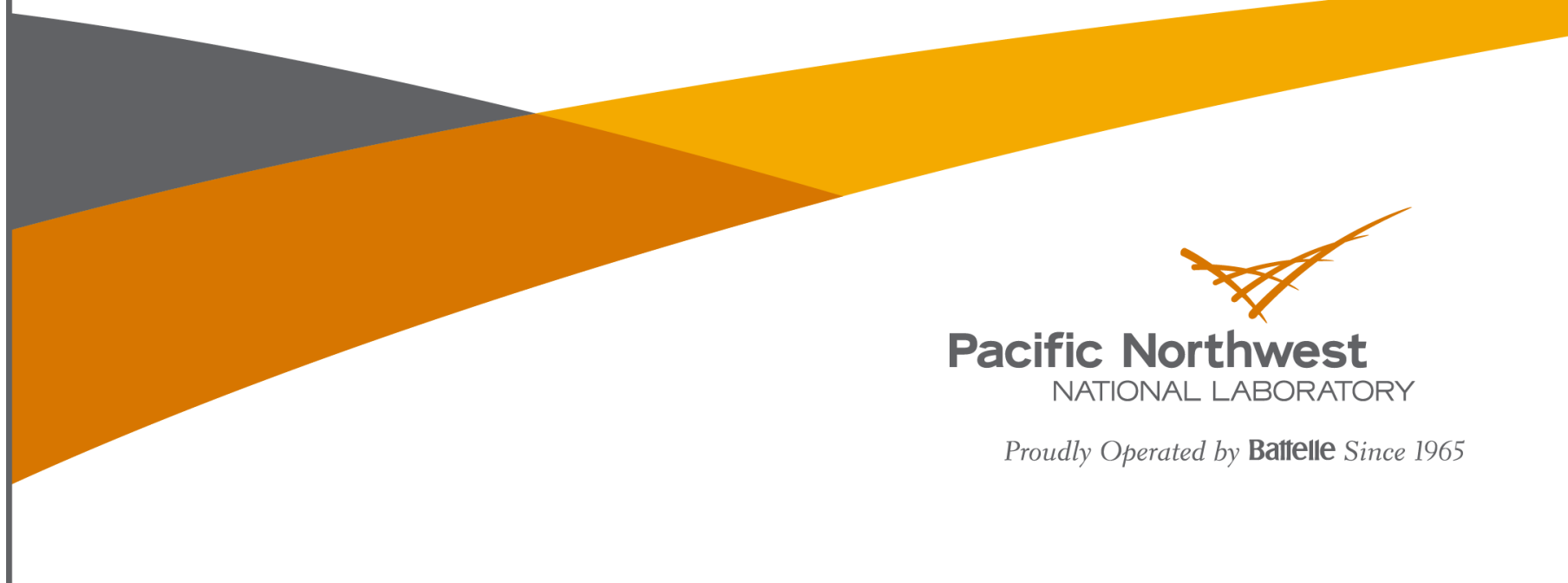




\title{
DISCLAIMER
}

This report was prepared as an account of work sponsored by an agency of the United States Government. Neither the United States Government nor any agency thereof, nor Battelle Memorial Institute, nor any of their employees, makes any warranty, express or implied, or assumes any legal liability or responsibility for the accuracy, completeness, or usefulness of any information, apparatus, product, or process disclosed, or represents that its use would not infringe privately owned rights. Reference herein to any specific commercial product, process, or service by trade name, trademark, manufacturer, or otherwise does not necessarily constitute or imply its endorsement, recommendation, or favoring by the United States Government or any agency thereof, or Battelle Memorial Institute. The views and opinions of authors expressed herein do not necessarily state or reflect those of the United States Government or any agency thereof.

\author{
PACIFIC NORTHWEST NATIONAL LABORATORY \\ operated by \\ BATTELLE \\ for the \\ UNITED STATES DEPARTMENT OF ENERGY \\ under Contract DE-AC05-76RL01830
}

Printed in the United States of America
Available to DOE and DOE contractors from the Office of Scientific and Technical Information,
P.O. Box 62, Oak Ridge, TN 37831-0062;
ph: (865) 576-8401
fax: $(865)$ 576-5728
email: reports@adonis.osti.gov

\begin{abstract}
Available to the public from the National Technical Information Service, U.S. Department of Commerce, 5285 Port Royal Rd., Springfield, VA 22161 ph: (800) 553-6847 fax: $(703) 605-6900$ email: orders@ntis.fedworld.gov online ordering: http://www.ntis.gov/ordering.htm
\end{abstract}

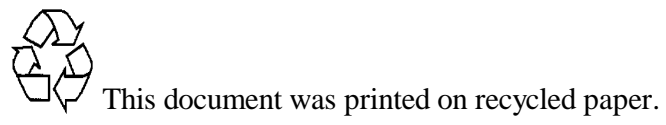




\section{CCSI Risk Estimation: An Application of Expert Elicitation}

DW Engel

AC Dalton

October 2012

Prepared for

the U.S. Department of Energy

under Contract DE-AC05-76RL01830

Pacific Northwest National Laboratory

Richland, Washington 99352 


\section{Contents}

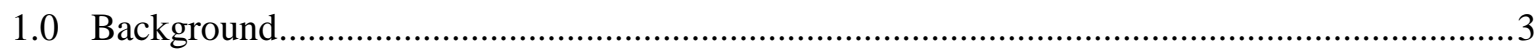

2.0 Expert Elicitation Background and Significance................................................................ 4

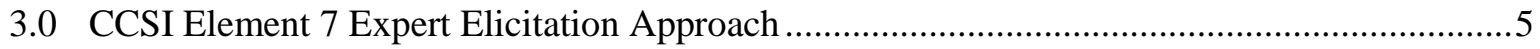

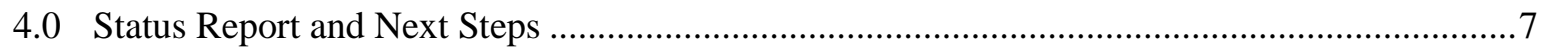

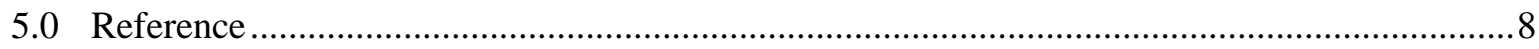

\section{Figures}

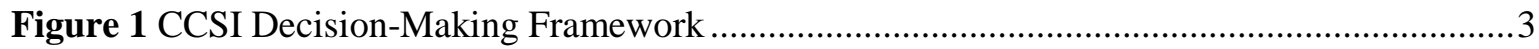

Figure 2 CCSI Risk Factor Expert Elicitation Approach ...................................................... 6

\section{Tables}

Table 1 Risk Categories 


\subsection{Background}

The Carbon Capture Simulation Initiative (CCSI) is a multi-laboratory simulation-driven effort to develop carbon capture technologies with the goal of accelerating commercialization and adoption in the near future. One of the key CCSI technical challenges is representing and quantifying the inherent uncertainty and risks associated with developing, testing, and deploying the technology in simulated and real operational settings. To address this challenge, the CCSI Element 7 team developed a holistic risk analysis and decision-making framework (shown below). One component of the risk analysis centers on the assessment of financial risks related to technology deployment and operations (Engel et al. 2012). Technical risk model captures risk factors such system efficiency, reliability, and safety. In addition, the CCSI technology readiness level (TRL) assessment instrument has been developed and is tailored specifically for the CCSI technical components to evaluate the gap between the current and desired degrees of technology maturity (Engel et al. 2012). The TRL assessment results will provide input into both the technical risk and financial risk models. Another element in CCSI holistic risk analysis and decision-making framework is structured risk elicitation with subject matter experts (SMEs) to identify and incorporate additional risk factors beyond those represented in the risk models and TRLs. In this

context, additional

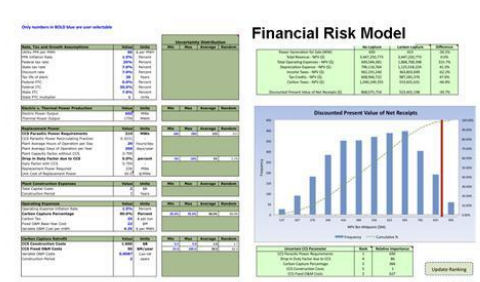

Decision Making Framework
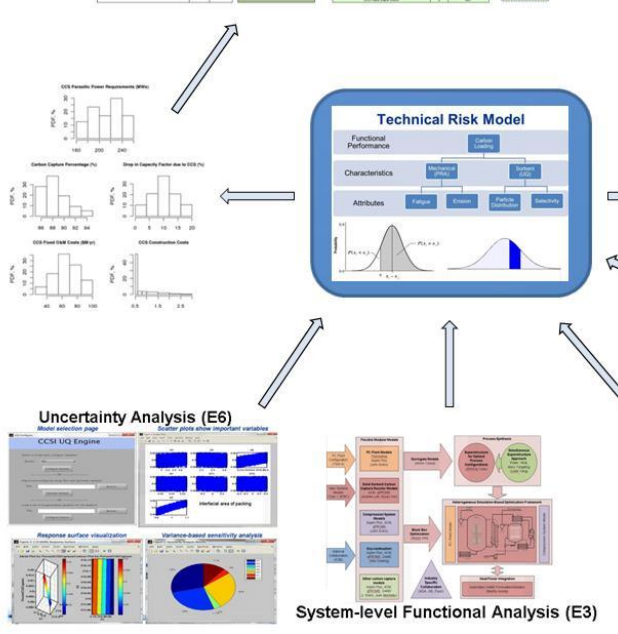

Figure 1 CCSI Decision-Making Framework technical risk factors as well as non-technical risk factors such as economic, policy, and legal risks (Miller et al. 2011) are also taken into consideration to inform the development of a holistic CCSI risk assessment framework and a comprehensive risk mitigation strategy. The purpose of this report is to document this last prong of the risk assessment effort, structured systematic expert elicitation, to identify additional risk factors. To that end, we review the significance of and dominant

approaches to expert elicitation, describe the CCSI risk elicitation plan and implementation strategies, and conclude by discussing the next steps and highlighting the contribution of risk elicitation toward the achievement of the overarching CCSI objectives. 


\subsection{Expert Elicitation Background and Significance}

Expert elicitation, especially probability elicitation, has been widely used in risk analysis, decision analysis, and performance assessment (Hora 2009; Cooke 1991; Stael von Holstein and Matheson 1979). Experts' knowledge, experience, and insight is especially useful when the phenomenon of interest are poorly understood due to newness, rarity or complexity; or when "hard" data are limited or unavailable, data collection is expensive, or formal modeling is infeasible (Meyer and Booker 2001; Ayyub 2001). The extant literature on expert elicitation focuses on three major topics. One topic centers on elicitation methods, especially in the context of probabilistic risk analysis and belief network modeling (Cooke and Goossens 2004; Cooke 1991; Stael von Holstein and Matheson 1979; Mosleh et al. 1988). Qualitative elicitation approaches such as focus groups and scenario analysis can yield decision alternatives, risk rankings, and risk scenarios (e.g. Dalkey and Helmer 1963) while quantitative elicitation translates experts' opinions about uncertainty into probability distributions. Despite procedural variations (cf. Cooke 1991; Spetzler and Stael von Holstein 1975; DeWispelare et al. 1995; and Boring et al. 2005), the probability elicitation process is typically conducted in five steps. First, a decision problem is defined. Next, in the preparation and setup stage, the elicitor identifies, recruits, motivates, and trains experts. Then, the elicitor structures, frames and presents the elicitation questions. The experts proceed to provide assessments, which will be carefully documented (Renooij 2001). Lastly, if multiple experts are used, their input is aggregated behaviorally or mathematically (Clemen and Winkler 1999). Some studies within this stream of research also investigate the effects of different methods of presenting elicitation questions on the elicitation outcomes. Common presentation methods include probability scales, gambling/betting, and the probability wheel (Ranooij 2001; Druzdzel and van der Gaag 1995). Recent research applied preference methods such as the pairwise comparison approach used in marketing research to probability elicitation with considerable success (Walsh et al. 2010; Dalton et al. 2012). In probability elicitation, both predictive and structural elicitation questions are asked. Predictive questions ask experts to predict the value of the dependent variables given a series of independent variable values, while structural questions ask experts to provide assessments of the prior distribution and parameters (Kadane and Wolfson, 1998).

Another focal point of the expert elicitation literature intersects with psychological research on heuristics and biases, and explores the effects of human cognitive patterns on elicitation. Heuristics refer to the effort-reduction methods employed by decision makers to alleviate judgmental burdens, and judgment biases refer to prejudicial mental behavior that undermines rational decision making (Arnott 1998; Shah and Oppenheimer, 2008; Simon 1990; Tversky and Kahneman 1974). Prominent classes of heuristics include representativeness (assessments based on similarity between events), availability (assessments based on one's ability to recall past events), and adjustment and anchoring (assessments bounded by initial judgment) (Tversky and Kahneman 1974). Remus and Kottemann (1986) grouped heuristics based on their relevance to data presentation and information processing (Remus and Kottemann 1986); Hogarth (1987) categorized heuristics based on the four stages in decision-making ranging from “acquisition, processing, output, to action" (Arnott 1998, p. 28; see Arnott 1998 for a comprehensive review). In probabilistic risk elicitation, the most widely observed effects of judgmental biases are systematic under- or over-estimation and overconfidence (Mosleh et al. 1988). Approaches to reducing systematic bias and overconfidence include calibration training (Lichtenstein et al. 1982) and the encouragement of considering both affirmative and contradicting evidence in experts' decision making (Spetzler and von Holstein 1975). Moreover, improving the formulation of decision problems may prove useful for enhancing the quality of elicitation. For example, problem decomposition, the idea of breaking a decision problem into multiple smaller decision problems, allows experts to assess probabilities for each component of the decision question, which is then synthesized into an overall probability estimate. Additionally, transforming a probability elicitation question into a less statistically esoteric format, such 
as a betting game or pairwise comparison of decision options, may be more appropriate for experts with limited statistical knowledge.

Another key component in the research on expert elicitation documents techniques of aggregating input from multiple experts (Clemen and Winkler 1990; Winkler 1981). Generally, combination can be implemented behaviorally and mathematically. In the absence of expert interaction, an opinion pool can help aggregate assessments. Elicitors can assign different weights to different experts, especially according to the accuracy of their assessments from training/calibration sessions. For a detailed discussion on mathematical combination methods, see Clemen and Winkler (1999). If interaction is permitted among experts, the elicitor can distribute the assessments among the experts to achieve a group consensus. An example of this approach is the Delphi technique, which seeks to derive a consensus through iterative deliberation among all the experts. Note, however, the interactive group consensus method may be influenced by dominant personalities in the group. In terms of performance, some evidence suggests that mathematical aggregation outperforms behavioral aggregation (Cooke and Goossens 2004; Clemen and Winkler 1999; Hora 2009) while others suggest the determination of aggregation approach should be dictated by the decision tasks (DeWispelare et al. 1995).

Expert elicitation has been applied to a broad range of domains, ranging from environmental protection (Salvi and Gaston 2004), infrastructure vulnerability (Vrijling et al. 2004), accident consequence modeling (Cooke and Goossens 2000), nuclear waste regulations (DeWispelare et al. 1995), medical diagnosis (Lau and Leung 1999) to carbon capture and storage technology (Chan et al. 2011). Regardless of the variations in elicitation approaches and the application domains, for expert elicitation to maintain its scientific rigor as a consensus methodology, it is imperative that the elicitation methods, processes, and tools are transparent and free of biases; the selection of expertise is based on relevant expertise to ensure proper domain coverage while minimizing bias; and the analysis approach and elicitation results are repeatable (Cooke and Goossens 2000).

\subsection{CCSI Element 7 Expert Elicitation Approach}

The fundamental purpose of CCSI expert elicitation activities is to enable and facilitate the sharing of relevant, diverse, and highly specialized knowledge to collectively inform the risks associated with the development and deployment of carbon capture technologies. Engagement of the CCSI risk analysis team with experts for risk elicitation is critical. First, carbon capture technology is relatively new and highly complex with a host of potentially latent risk factors that might compromise the success of the technology if left unaddressed. Thus, leveraging the diverse expertise on the project team can help identity and address these latent risk factors in addition to the risks captured by the financial risk, technical risk, and technical maturity assessments. Furthermore, given the focus on simulation and modeling, some system features might not be modeled due to their fine granularity. These under-specified system characteristics might present potentially significant risks, thus demanding a finer-grained risk analysis of the modeling assumptions, parameters, operational risks, and those characteristics that cannot be captured by formal modeling but nonetheless have operational impact. Additionally, the engagement of experts and stakeholders through elicitation early in the technology development process provides an excellent opportunity for continuous and iterative risk communication to help them better understand and address risks as the technology development unfolds, resulting in greater risk reduction and technology acceptance by the stakeholders.

The CCSI Element 7 is developing an elicitation approach that combines both qualitative risk rankings and quantitative risk assessments to capture the under-specified and not-yet-modeled risk factors in carbon capture technologies. Figure 2 provides a step-by-step illustration of the elicitation activities. 


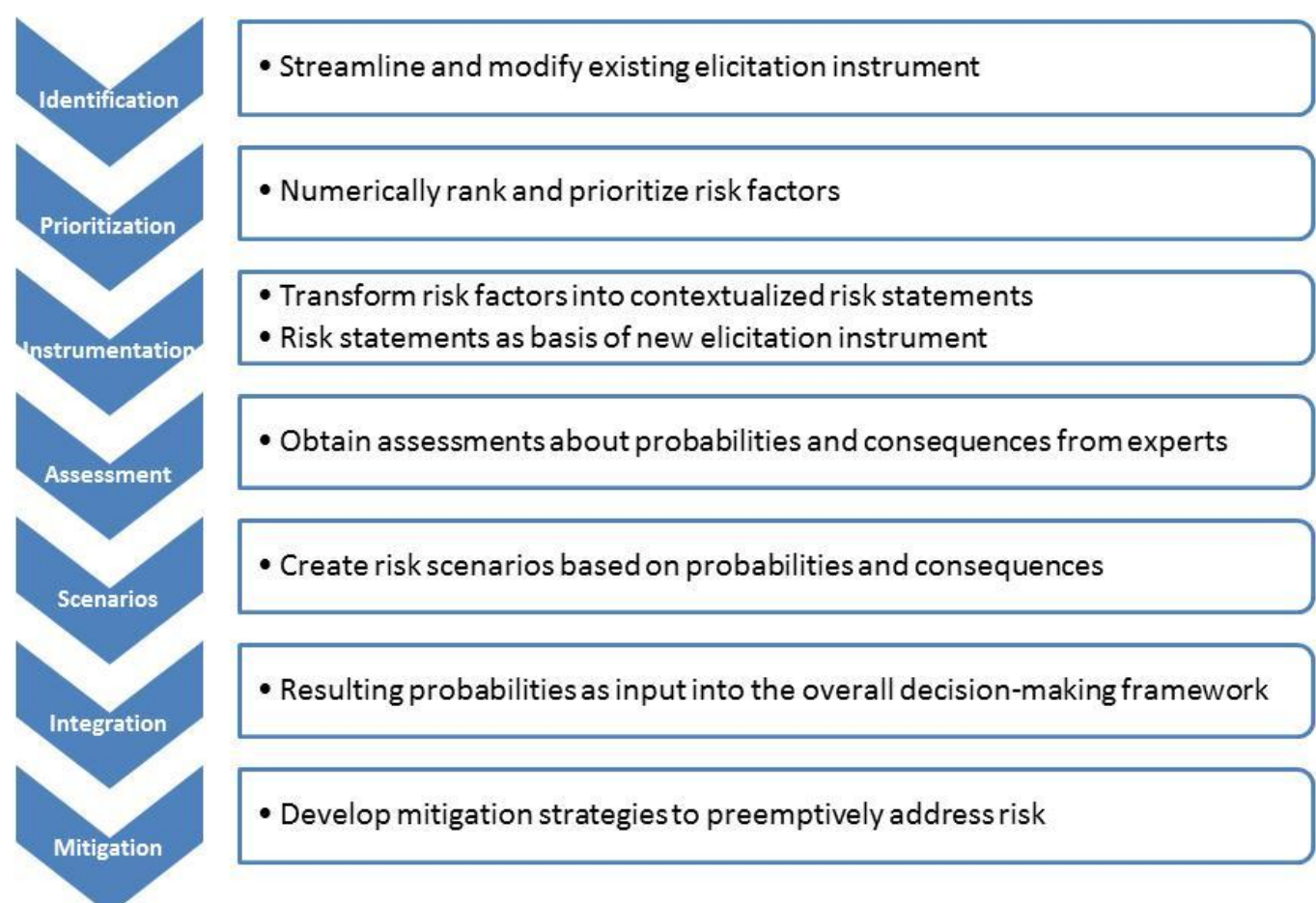

Figure 2 CCSI Risk Factor Expert Elicitation Approach

The elicitation plan will build on the previous solid sorbent $\mathrm{CO} 2$ capture technology risk elicitation framework (see Appendix ). This framework identified five main risk drivers, including (1) knowledge maturity and development capacity, (2) uncertainties related to financial/regulatory/public opinion, (3) technical performance in testing and deployment, (4) costs and efficiency, and (5) compatibility between simulation tools and physical systems. An extensive list of potential risk factors (totaling 98) was organized into three major risk dimensions: technical risk, economic risk, and regulatory/public risk. Each risk category was further operationalized by multiple sub risk factor categories as shown in the following table:

Table 1 Risk Categories

\begin{tabular}{|l|l|}
\hline $\begin{array}{c}\text { Major Risk Factor } \\
\text { Category }\end{array}$ & Sub Risk Factor Category \\
\hline \multirow{4}{*}{ Technical Risk } & overall technical maturity \\
\cline { 2 - 3 } & engineering implementation \\
\cline { 2 - 3 } & chemical viability \\
\cline { 2 - 3 } & operability \\
\hline \multirow{5}{*}{ Economic Risk } & overall cost effectiveness \\
\cline { 2 - 3 } & financial viability \\
\cline { 2 - 3 } & chemical synthesis costs \\
\cline { 2 - 3 } & supply costs \\
\cline { 2 - 3 } & $\begin{array}{l}\text { processing and disposal } \\
\text { costs }\end{array}$ \\
\cline { 2 - 3 } & shipping costs of adsorbent \\
\cline { 2 - 3 } & existing facilities \\
\cline { 2 - 3 } & sequestration interface \\
\hline
\end{tabular}




\begin{tabular}{|l|l|}
\hline $\begin{array}{c}\text { Major Risk Factor } \\
\text { Category }\end{array}$ & Sub Risk Factor Category \\
\hline & confidence in simulation \\
\hline \multirow{4}{*}{ Regulatory/Public Risk } & regulatory engagement \\
\cline { 2 - 2 } & permitting \\
\cline { 2 - 2 } & public perception \\
\cline { 2 - 2 } & cost impacts \\
\hline
\end{tabular}

Using this risk factor list, the CCSI Element 7 team will organize a qualitative risk factor identification exercise with a panel of experts representing all the task teams within the initiative as well as from industry partners. This exercise will accomplish two objectives: (1) to eliminate irrelevant risk factors or risk categories; and (2) to incorporate relevant factors/risk categories that are missing from the list. With a streamlined list of potential risk factors, the experts will participate in a risk ranking elicitation where they will be asked to rank each risk factor on a numeric scale. The risk rankings will produce relevance weights for each risk factor, and help sharpen the focus of the follow-up elicitation effort. Once the priority risk factors are identified based on rankings, the elicitation team will develop contextualized risk statements for these factors and these statements will be pooled to produce a new CCSI risk factor expert elicitation instrument to be used in a systematic quantitative risk assessment. Risk is characterized by the severity of potentially adverse events and the likelihood of the occurrences of these events. To that end, we will distribute the instrument and ask expert respondents to provide a likelihood assessment and related magnitude assessment for each risk statement on a numerical scale (for an example instrument, see Hunton and Williams 2008). Mathematical aggregation algorithms will be employed to produce a combined probability distribution for each risk factor (Clemen and Winkler 1999). Next, the Element 7 team will create future risk scenarios using the identified risk factors to forecast failure rates over varying time horizons. For example, two programmatic performance criteria, a minimum $90 \%$ carbon capture efficiency rate; and a 30\% cost increase ceiling for carbon capture technology in long-term operations, can be used in risk scenario development to compare the current and the desired level of technical capabilities. Again, experts will each provide a probabilistic risk forecast for these scenarios and their input will be aggregated. The resulting probability distributions from the scenarios as well as from the elicitation questionnaire will be integrated into the overall risk analysis framework to improve the quality of the risk assessment of carbon capture technology as a whole. A final step in this risk assessment effort requires the development of a targeted risk mitigation strategic plan to address the risks and reduce their adverse effects on CCSI program outcomes. It is important to note that the CCSI expert elicitation effort will be iterative in nature, and will closely follow the progress in carbon capture technology simulation and testing.

\subsection{Status Report and Next Steps}

The success of expert elicitation critically depends on the active collaboration across CCSI task teams and the support from the external stakeholders. To enhance the collaboration within CCSI for the expert elicitation, effort is under way to engage scientists from other Element teams to help modify and refine the technology maturity levels (TRL) questionnaire. The CCSI E7 Team has created a wiki-based elicitation and model development tool to enable novel, probabilistic technology maturity assessment by CCSI project teams (E1, E2, E3, and E97) as well as external experts. This collaborative effort will pave the way for more elaborate and involved elicitation activities described in this report. With respect to engagement with external experts, the Element 7 team conducted a site visit to Eastman Chemical Company in August 2012. This visit offered an invaluable learning opportunity to understand how risk analysis is routinely performed in business organizations. It also signals the establishment of a solid 
CCSI-industry partnership crucial for expert elicitation tasks in the near future. It is anticipated that in the coming program year, greater attention will be invested in the elicitation-driven risk assessment to compliment the financial and technical risk analyses and technology maturity risk modeling that are the focus of the present program year. If successful, the expert-driven risk elicitation will contribute to a better understanding of the potential vulnerabilities and risks in developing, testing, deploying, and commercializing carbon capture technologies, and provide mitigation strategies to reduce risk and uncertainty, and help the technology reach the stage of commercialization more reliability and rapidly.

\subsection{Reference}

Arnott, D. 1998. A Taxonomy of Decision Biases. Unpublished Technical Report. Monash University School of Information Management \& Systems.

Ayyub, Bilal. 2001. A Practical Guide on Conducting Expert-Opinion Elicitation of Probabilities and Consequences for Corps Facilities. IWR Report 01-R-01. U.S. Army Corps of Engineers Institute for Water Resources, Alexandria, VA 22315-3868

Boring, R., Gertman, D., Joe, J., Marble, J., Galyean, W., Blackwood, L., et al. (2005). Simplified Expert Elicitation Guideline for Risk Assessment of Operating Events. Idaho Falls, ID: Idaho National Laboratory.

Chan, G., Anadon, G, Diaz, L, Chan, M, and L. Audrey. Expert Elicitation of Cost, Performance, and R D\&D Budgets for Coal Power with CCS. Energy Procedia, Volume 4 (2011): 2685-2692.

Clemen, Robert T., and Robert L. Winkler. " Combining Probability Distributions from Experts in Risk Analysis." Risk Analysis 1919 (1999): 187-203.

Cooke, R. M., \& Goossens, L. H. J. (2004). Expert Judgment Elicitation for Risk Assessments of Critical Infrastructures. Journal of Risk Research, 7(6), 643-656.

Cooke, R. M., \& Goossens, L. H. J. (2000). Procedures Guide for Structured Expert Judgment in Accident Consequence Modeling. Radiation Protection Dosimetry, 90(3), 303-309.

Cooke, R. M. 1991. Experts in Uncertainty - Opinion and Subjective Probability in Science. Environmental Ethics and Science Policy Series. New York,: Oxford University Press.

Dalkey, Norman, and Olaf Helmer. "An Experimental Application of the Delphi Method to the Use of Experts." Management Science 9, no. 3 (1963): 458-67.

Dalton, Angela, Alan Brothers, Stephen Walsh, and Paul Whitney. "Expert Elicitation Method Selection Process and Method Comparison." In Neuroscience and the Economics of Decision-Making (A. Innocenti and A. Sirigu, ed.), 182-93. New York, NY: Routledge, 2012.

Dewispelare, A. R., Herren, L. T., \& Clemen, R. T. (1995). The use of probability elicitation in the highlevel nuclear waste regulation program. International Journal of Forecasting, 11(1), 5-24.

Druzdzel, MJ. and Van der Gaag, LC, 1995, Elicitation of Probabilities for Belief Networks: Combining Qualitative and Quantitative Information, Proceedings of the Eleventh Conference on Uncertainty in Artificial Intelligence, 141-148, Los Altos, CA.

Engel, D. W., Letellier, B., Edwards, B., LeClaire, r., \& Jones, E. (2012). New Technical Risk Management Development for Carbon Capture Process. Paper presented at $11^{\text {th }}$ Annual Carbon Capture, Utilization and Sequestration Conference, Pittsburgh, Pennsylvania, April 30-May 3.

Garthwaite, Paul, H., Joseph Kadane, B. , and Anthony O'Hagan. "Statistical Methods for Eliciting Probability Distributions." Journal of the American Statistical Association 100, no. 470 (2005): 680.

Hogarth, R. (1987). Judgment and Choice: The Psychology of Decision (2nd ed.).Chichester, UK: Wiley.

Hora, Stephen C. Expert Judgment in Risk Analysis. (2009). Non-published Research Report. Paper 120. http://research.create.usc.edu/nonpublished_reports/120

Hunton \& Williams. (2008). Risk Factor Questionnaire for Coal Power Plants with Carbon Capture \& Storage (CCS). Washington, DC. CCS Alliance for Risk-based Policy. 
Kadane, Joseph, and Lara J. Wolfson. "Experiences in Elicitation." Journal of the Royal Statistical Society: Series D (The Statistician) 47, no. 1 (1998): 3.

Lau, Aik-Hiang, and Tze Yun Leong. "Probes: A Framework for Probability Elicitation from Experts." In American Medical Informatics Association Annual Fall Symposium, 1999.

Lichtenstein, S., Fischhoff, B., \& Phillips, L.D. (1982). Calibration of probabilities: The state of the art to 1980. In D. Kahneman, P. Slovic \& A. Tversky (Eds.), Judgment under Uncertainty: Heuristics and Biases (pp. 306-334). New York: Cambridge University Press.

Meyer, M. A., and J. M. Booker, Eliciting and Analyzing Expert Judgment: A Practical Guide, Philadelphia, Pa.: Society for Industrial and Applied Mathematics and the American Statistical Association, 2001.

Miller, David C., Deborah A. Agarwal, Xin Sun, and Charles Tong. CCSI and the role of advanced computing in accelerating the commercial deployment of carbon capture systems. In Proceedings of the SciDAC 2011 Conference, Denver, CO, July 2011.

Mosleh, A., Bier, V., and G. Apostolakis. "A Critique of Current Practice for the Use of Expert Opinions in Probabilistic Risk Assessment. Reliability Engineering and System Safety, 20 (1988): 63-85.

Remus, W.E., \& Kottemann, J.E. (1986). Toward intelligent decision support systems: An artificially intelligent statistician. MIS Quarterly, 10 (4), 403-418.

Renooij, Silja. "Probability Elicitation for Belief Networks: Issues to Consider." Knowledge Engineering Review, 16, no. 3 (2001): 255-69.

Salvi, O., \& Gaston, D. (2004). Risk assessment and risk decision-making process related to hazardous installation in France. Journal of Risk Research, 7(6), 599-608

Shah, A. K., \& Oppenheimer, D. M. (2008). Heuristics Made Easy: An Effort-Reduction Framework. Psychological Bulletin, 134(2), 207-222.

Spetzler, Carl S., and S. Stael Von Holstein Carl-Axel. "Probability Encoding in Decision Analysis." Management Science 22, no. 3 (1975): 340-58.

Stael von Holstein, C.A.S. \& Matheson, J.E. (1979). A Manual for Encoding Probability Distributions, SRI International, Menlo Park.

Tversky, A., and Kahneman, D. (1974). Judgment under Uncertainty: Heuristics and Biases. Science, 4157(2), 1124-1131.

Vrijling, J. K., Van Gelder, P. H. A. J. M., Goossens, L. H. J., Voortman, H. G., \& Pandey, M. D. (2004). A framework for risk criteria for critical infrastructures: fundamentals and case studies in the Netherlands. Journal of Risk Research, 7(6), 569-579.

Walsh, Steve, Angela C. Dalton, and Amanda White. Parameterizing Bayesian Network Representations of Social-Behavioral Models by Expert Elicitation: A Novel Application of Conjoint Analysis. Paper accepted for the Workshop on Current Issues in Predictive Approaches to Intelligence and Security Analytics, Vancouver, BC, Canada. IEEE Intelligence and Security Informatics Conference, May 26, 2010.

Winkler, R. L. Combining probability distributions from dependent information sources, Management Science, 27 91981), pp. 479-88. 


\section{Appendix}

\section{Risk Factor Rating Form for Solid Sorbent $\mathrm{CO}_{2}$ Capture Concerns related to a 1-MW demonstration test}

\begin{tabular}{|l|c|c|c|c|}
\hline \multicolumn{4}{|c|}{ Area of Expertise or Interest for $\mathbf{C O}_{2}$ Capture (check all that apply) } \\
\hline Technical & Economic & Management & Regulatory & Public \\
\hline & & & \\
\hline \multicolumn{5}{|c|}{ Comments or Description of Area of Expertise } \\
\hline
\end{tabular}

\section{Instructions:}

For the present purpose, "Risk" is any action, outcome, or result that could adversely affect the success of a hypothetical 1-MW slip stream demonstration test for the application of a solid sorbent $\mathrm{CO}_{2}$ capture technology.

Categorical Risk Factors are presented in a tabular outline format. Check one box to assign a Risk Level $(1-5$ from low to high) for each factor. Notional definitions of the Risk Levels are provided below. You may "skip" any Risk Factor, but please record your decision in the box provided.

Following your rating of each Risk Factor, please, enter any/all of the Risk Drivers $(A-F)$ that best describe the reasons for your rating. You are encouraged to provide comments at any time and to add additional Risk Factors to the table.

Please, return your results to:

Bonnie Koch

bkoch@lanl.gov

(505) 665-1248

\begin{tabular}{|l|l|}
\hline \multicolumn{2}{|l|}{ Risk Levels } \\
\hline Level 1 & Risk Factor contributes little residual risk (issue is well understood and studied) \\
\hline Level 2 & $\begin{array}{l}\text { Risk Factor contributes some residual risk (issue shows signs of success and acceptability, but retains } \\
\text { uncertainties) }\end{array}$ \\
\hline Level 3 & Risk Factor represents legitimate concerns (issue shows systematic study, but lacks definitive conclusions) \\
\hline Level 4 & Risk Factor carries significant uncertainty and/or potential project impact (issue sparsely investigated to date) \\
\hline Level 5 & Risk Factor may dominate the project risk profile (issue is formative and as yet undemonstrated or unproven) \\
\hline
\end{tabular}

Use these Levels to rate Risk Factors from 1 through 5 (low risk to high risk)

\begin{tabular}{|c|l|}
\hline \multicolumn{2}{|l|}{ Risk Drivers } \\
\hline A & Degree of maturity in terms of knowledge, understanding, or ability to develop \\
\hline B & External uncertainties in the areas of permitting, finance, or regulatory and public concerns \\
\hline C & Technical performance during tests or deployment, etc. \\
\hline D & Cost versus efficiency relative for use, manufacturability, operability, or other factors \\
\hline E & Incompatibility/Insufficiency of simulation tools relative to physics and engineering regime \\
\hline F & Does not seem to apply in this context \\
\hline
\end{tabular}

Use these Drivers to best explain the reasons for your Risk Level assignment. 


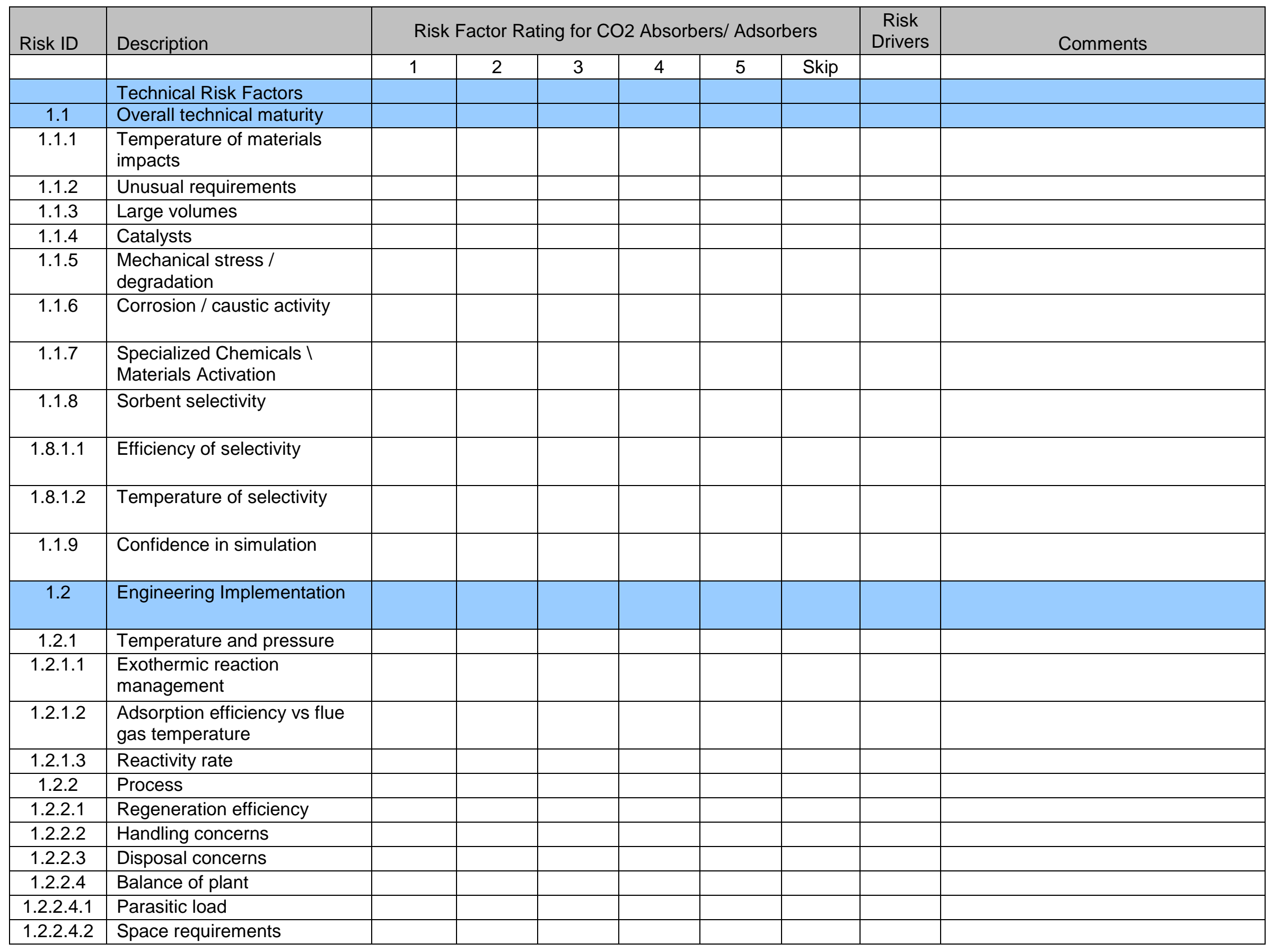

Page 1 


\begin{tabular}{|c|c|c|c|c|c|c|c|c|c|}
\hline \multirow{3}{*}{$\begin{array}{l}\text { Risk ID } \\
1.2 .1 .4 .3\end{array}$} & \multirow{3}{*}{$\begin{array}{l}\text { Description } \\
\text { Capture performance }\end{array}$} & \multicolumn{6}{|c|}{ Risk Factor Rating for $\mathrm{CO} 2$ Absorbers/ Adsorbers } & \multirow{3}{*}{$\begin{array}{l}\text { Risk } \\
\text { Drivers } \\
\end{array}$} & \multirow{2}{*}{ Comments } \\
\hline & & 1 & 2 & 3 & 4 & 5 & Skip & & \\
\hline & & & & & & & & & \\
\hline 1.2.1.4.4 & Capture quality & & & & & & & & \\
\hline 1.2.1.4.5 & Cost of electricity & & & & & & & & \\
\hline 1.2.1.4.6 & Process water & & & & & & & & \\
\hline 1.2.1.4.7 & Construction costs & & & & & & & & \\
\hline 1.2 .3 & Extraction efficiency & & & & & & & & \\
\hline 1.2.3.1 & Number of cycles & & & & & & & & \\
\hline 1.2 .3 .2 & Reactivity per cycle & & & & & & & & \\
\hline 1.2.3.3 & $\begin{array}{l}\text { Impacts due to gases other } \\
\text { than } \mathrm{CO} 2 \text { in waste stream }\end{array}$ & & & & & & & & \\
\hline 1.2 .4 & Construction infrastructure & & & & & & & & \\
\hline 1.2.4.1 & Unique challenge & & & & & & & & \\
\hline 1.2 .4 .2 & Engineering performance & & & & & & & & \\
\hline 1.2 .4 .3 & Proven experimentally & & & & & & & & \\
\hline $1.2 . .4 .4$ & Supply chain & & & & & & & & \\
\hline 1.2.4.5 & Capacity & & & & & & & & \\
\hline 1.3 & Chemical Viability & & & & & & & & \\
\hline 1.3 .1 & Physics & & & & & & & & \\
\hline 1.3.1.1 & Solids surface & & & & & & & & \\
\hline 1.3 .1 .2 & Liquid liquid & & & & & & & & \\
\hline 1.3.1.3 & Liquid gas & & & & & & & & \\
\hline 1.3 .2 & Rate constants & & & & & & & & \\
\hline 1.3 .3 & Reaction rate or reactivity & & & & & & & & \\
\hline 1.3 .4 & Thermodynamics & & & & & & & & \\
\hline 1.3 .5 & Established theory & & & & & & & & \\
\hline 1.3 .6 & Simulated pressure rates & & & & & & & & \\
\hline 1.3 .7 & Lab scale experiments & & & & & & & & \\
\hline 1.4 & Operability & & & & & & & & \\
\hline 1.4 .1 & Process safety & & & & & & & & \\
\hline 1.4.1.1 & Accident scenarios & & & & & & & & \\
\hline 1.4 .1 .2 & Design controls & & & & & & & & \\
\hline 1.4.1.3 & Heavy loads & & & & & & & & \\
\hline 1.4 .2 & Component reliability & & & & & & & & \\
\hline 1.4 .2 .1 & Plant capacity & & & & & & & & \\
\hline
\end{tabular}

Page 2 


\begin{tabular}{|c|c|c|c|c|c|c|c|c|c|}
\hline \multirow{3}{*}{$\begin{array}{l}\text { Risk ID } \\
1.4 .2 .2\end{array}$} & \multirow{3}{*}{$\begin{array}{l}\text { Description } \\
\text { Control feedback }\end{array}$} & \multicolumn{6}{|c|}{ Risk Factor Rating for $\mathrm{CO} 2$ Absorbers/ Adsorbers } & \multirow{3}{*}{$\begin{array}{c}\text { Risk } \\
\text { Drivers } \\
\end{array}$} & \multirow{2}{*}{ Comments } \\
\hline & & 1 & 2 & 3 & 4 & 5 & Skip & & \\
\hline & & & & & & & & & \\
\hline 1.4.2.3 & $\begin{array}{l}\text { Operator training / } \\
\text { performance }\end{array}$ & & & & & & & & \\
\hline 1.4 .4 & Process control stability & & & & & & & & \\
\hline 1.4 .5 & Consumables in feedstream & & & & & & & & \\
\hline 1.4.5.1 & Solid adsorber & & & & & & & & \\
\hline \multirow[t]{2}{*}{1.4 .5 .2} & Process chemicals & & & & & & & & \\
\hline & Economic Risk Factors & & & & & & & & \\
\hline 2.1 & Overall cost effectiveness & & & & & & & & \\
\hline 2.1 .1 & $\begin{array}{l}\text { Able to meet DOE } \\
\text { performance goals }\end{array}$ & & & & & & & & \\
\hline 2.2 & Financial Viability & & & & & & & & \\
\hline 2.2 .1 & Construction loan guarantees & & & & & & & & \\
\hline 2.2 .2 & Rate increase approval & & & & & & & & \\
\hline 2.2 .3 & Portfolio capacity / expansion & & & & & & & & \\
\hline 2.2 .4 & Phased capitalization & & & & & & & & \\
\hline 2.2 .5 & $\begin{array}{l}\text { Risk sharing across emerging } \\
\text { industry }\end{array}$ & & & & & & & & \\
\hline 2.2 .6 & Performance guarantees & & & & & & & & \\
\hline 2.2 .7 & Liability indemnification & & & & & & & & \\
\hline 2.2 .8 & Ability to subsidize & & & & & & & & \\
\hline 2.3 & Chemical synthesis costs & & & & & & & & \\
\hline 2.4 & Supply costs & & & & & & & & \\
\hline 2.5 & $\begin{array}{l}\text { Processing and disposal } \\
\text { costs }\end{array}$ & & & & & & & & \\
\hline 2.5 .1 & Retrofit costs & & & & & & & & \\
\hline 2.5 .2 & Regeneration costs & & & & & & & & \\
\hline 2.5 .3 & Storage costs & & & & & & & & \\
\hline 2.5 .4 & Disposal costs & & & & & & & & \\
\hline 2.5 .5 & $\begin{array}{l}\text { Separation of CO2 from } \\
\text { absorbant }\end{array}$ & & & & & & & & \\
\hline 2.6 & Shipping costs of adsorbant & & & & & & & & \\
\hline 2.7 & Existing facilities & & & & & & & & \\
\hline
\end{tabular}

Page 3 


\begin{tabular}{|c|c|c|c|c|c|c|c|c|c|}
\hline \multirow{2}{*}{ Risk ID } & \multirow{2}{*}{ Description } & \multicolumn{6}{|c|}{ Risk Factor Rating for $\mathrm{CO} 2$ Absorbers/ Adsorbers } & \multirow{2}{*}{$\begin{array}{c}\text { Risk } \\
\text { Drivers } \\
\end{array}$} & \multirow{2}{*}{ Comments } \\
\hline & & 1 & 2 & 3 & 4 & 5 & Skip & & \\
\hline 2.8 & Sequestration interface & & & & & & & & \\
\hline 2.9 & Confidence in simulation & & & & & & & & \\
\hline & $\begin{array}{l}\text { Regulatory / Public Risk } \\
\text { Factors }\end{array}$ & & & & & & & & \\
\hline 3.1 & Regulatory Engagement & & & & & & & & \\
\hline 3.1 .1 & Rate increase approval & & & & & & & & \\
\hline 3.1 .2 & Subsidies & & & & & & & & \\
\hline 3.1 .2 .1 & Construction subsidies & & & & & & & & \\
\hline 3.1.2.2 & Revenue compensation & & & & & & & & \\
\hline 3.1 .2 .3 & Loan guarantee & & & & & & & & \\
\hline 3.1 .3 & Emissions penalties & & & & & & & & \\
\hline 3.1 .4 & Carbon credits & & & & & & & & \\
\hline 3.1 .5 & Incentives & & & & & & & & \\
\hline 3.1 .5 .1 & Tax breaks & & & & & & & & \\
\hline 3.1 .5 .2 & Land grants & & & & & & & & \\
\hline 3.1 .5 .3 & Waivers & & & & & & & & \\
\hline 3.2 & Permitting & & & & & & & & \\
\hline 3.2 .1 & Public engagement & & & & & & & & \\
\hline 3.2 .2 & $\begin{array}{l}\text { Number of regulatory bodies / } \\
\text { levels }\end{array}$ & & & & & & & & \\
\hline 3.2 .3 & Coupling to sequestration & & & & & & & & \\
\hline 3.2 .4 & Coupling to Sox Nox & & & & & & & & \\
\hline 3.3 & Public perception & & & & & & & & \\
\hline 3.3 .1 & Process disposal and effluent & & & & & & & & \\
\hline 3.3 .2 & Plant encroachment & & & & & & & & \\
\hline 3.3 .3 .1 & Visual impact & & & & & & & & \\
\hline 3.3.3.2 & Vehicle congestion & & & & & & & & \\
\hline 3.3.2.3 & Impacts to local real estate & & & & & & & & \\
\hline 3.3 .3 & Global warming debate & & & & & & & & \\
\hline 3.3 .4 & Process safety (HAZOPS) & & & & & & & & \\
\hline 3.3 .5 & Sequestration coupling & & & & & & & & \\
\hline 3.4 & Cost impacts & & & & & & & & \\
\hline 3.4 .1 & Added costs to public & & & & & & & & \\
\hline
\end{tabular}

Page 4 


\begin{tabular}{|c|l|c|c|c|c|c|c|c|c|}
\hline Risk ID & Description & \multicolumn{6}{|c|}{ Risk Factor Rating for CO2 Absorbers/ Adsorbers } & $\begin{array}{c}\text { Risk } \\
\text { Drivers }\end{array}$ & Comments \\
\hline 3.4 .2 & $\begin{array}{l}\text { Economic growth } \\
\text { suppression }\end{array}$ & 1 & 2 & 3 & 4 & 5 & Skip & & \\
\hline
\end{tabular}

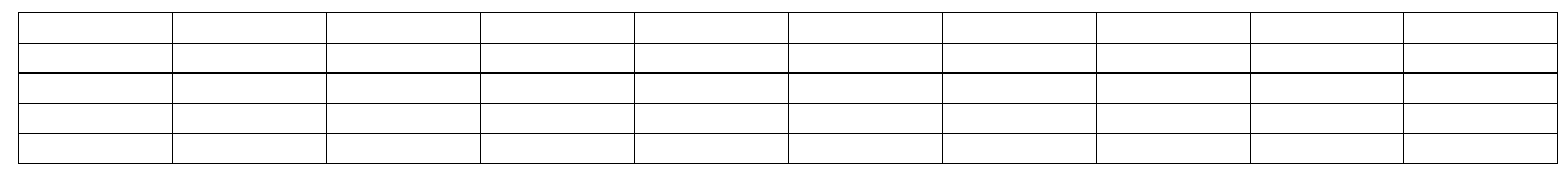




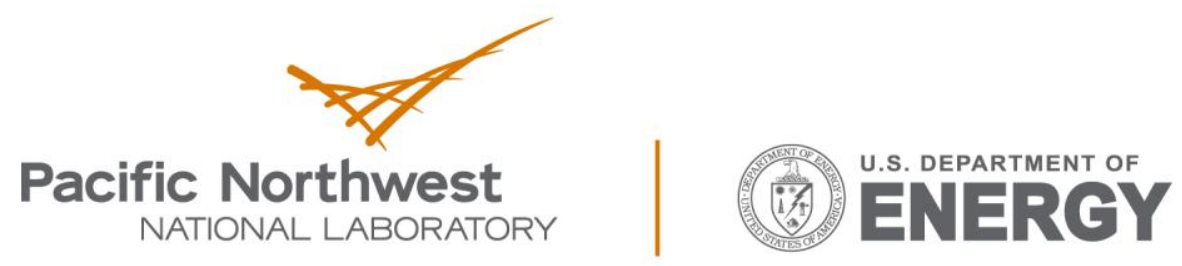

Proudly Operated by Battelle Since 1965

902 Battelle Boulevard

P.O. Box 999

Richland, WA 99352

1-888-375-PNNL (7665)

www.pnnl.gov 